\title{
Impactos Econômicos do Grande Prêmio Brasil de Fórmula 1
}

\author{
Economic Impacts of the Brazilian Formula 1 Grand Prix
}

\author{
Eduardo Amaral Haddad \\ Décio K. Kadota \\ Wilson Abrahão Rabahy ${ }^{3}$
}

\begin{abstract}
RESUMO: Este artigo tem como objetivo realizar uma avaliação econômica dos impactos econômicos gerados pela realização do Grande Prêmio Brasil de Fórmula 1 na cidade de São Paulo. A análise é feita com base num modelo de equilíbrio geral fundamentado na metodologia de insumo-produto, regionalizado para duas grandes regiōes (Estado de São Paulo e demais Estados do país). Também se utilizou, de forma integrada, um submodelo regionalizado para o Estado de São Paulo. Com base nessa metodologia, foi então possível avaliar os impactos daquele evento sobre a atividade econômica (valor da produção, renda e emprego), tanto para a própria cidade de São Paulo como para as demais regiōes do Estado de São Paulo e para o restante do país.
\end{abstract}

PALAVRAS-CHAVE: Fórmula 1; análise de insumo-produto; impactos econômicos de eventos esportivos; turismo; economia do turismo; teorometria.

ABSTRACT: This article aims to be an evaluation of economic impacts generated by Brazilian Grand Prix of Formula 1 on the city of São Paulo.

1. Coordenador de pesquisas da FIPE; professor doutor da FEA-USP; e Adjunct Research Assistant Professor, Regional Economics Applications Laboratory, University of Illinois. Contato: Av. Prof. Luciano Gualberto, 908 - FEA 1, Cidade Universitária - 05508-900 - São Paulo-sP; e-mail: ehaddad@usp.br.

2. Professor doutor da FEA-USP e pesquisador da FIPE. Contato: Av. Prof. Luciano Gualberto, 908 - FEA I, Cidade Universitária - 05508-900 - São Paulo-sP; e-mail: dkkadota@usp.br.

3. Professor doutor, titular do curso de Turismo da ECA-USP e pesquisador da FIPE. Contato: Av. Prof. Lúcio M. Rodrigues, 443 - Bloco B, Cidade Universitária - 05508-900 - São Paulo-sp; e-mail: rabahy@usp.br. 
The analysis uses an General Model Equilibrium based on the methodology of INPLT-OLTPLT, regionalized for two huge regions (Sāo Paulo State and other States). It was also used an integrated sub-model regionalized for Sāo Paulo State. Based on the methodology it was possible to evaluate the economic impact of the event on the economic activity (value of the production, level of income and job) as much in the proper city of Sāo Paulo, as for other regions from São Paulo State and the Country.

KEYWORDS: Formula 1; iNPUT-OUTPUr analysis; economic impacts of sports events; tourism; economy of the tourism; teorometrics.

\section{Introdução}

Este artigo apresenta um resumo da análise dos impactos econômicos do Grande Prêmio Brasil de Fórmula I realizado em 2003, evidenciando que se trata de uma atividade econômica adicional que anualmente ocorre no município de São Paulo. Apresenta, portanto, as estimativas dos impactos econômicos, diretos e indiretos, produzidos nos níveis da atividade econômica do município e do país, propiciados pelo conjunto de todas as atividades associadas à montagem e realização do evento, em termos dos aumentos de produção, de valor adicionado (ou renda) e de emprego, que não seriam observados se o evento não ocorresse.

Para isso apresenta-se inicialmente uma breve descrição da estrutura metodológica utilizada no estudo. Em seguida, apresentam-se as principais fontes de informações utilizadas e descrevem-se brevemente os procedimentos utilizados no tratamento dessas fontes. Finalmente, apresentam-se os resultados obtidos.

\section{Base metodológica}

Em linhas gerais, a modelagem dos impactos econômicos do Grande Prêmio Brasil de Fórmula 1 (GPBF1) foi desenvolvida em três estágios:

- Estágio 1: estimativa dos impactos diretos do GPBF1;

- Estágio 2: tradução das estimativas de impactos diretos em choques econômicos;

- Estágio 3: condução de simulações com modelos integrados de insumoproduto.
No caso dos impactos diretos desse evento, pode-se classificá-los em duas categorias:

a) gastos associados à montagem e operacionalização do evento (despesas da Prefeitura do Município de São Paulo - PMSP na preparação do autódromo e da empresa responsável pela organização e realização do evento);

b) gastos associados ao conjunto dos participantes do evento, constituído pelos pilotos e demais integrantes das equipes dos carros da Fórmula 1, pessoal das equipes de fornecedores de motores, de combustível, de pneus e demais componentes dos carros, autoridades e especialistas das entidades que regulam e fiscalizam a Fórmula 1; jornalistas e convidados internacionais (todos esses que doravante serão denominados de pessoal da Fórmula 1) e, finalmente, do público espectador.

Em relação ao público espectador, é pertinente destacar que se consideram apenas os gastos do público não-residente no município de São Paulo, nacional ou estrangeiro, que são os que efetivamente geram impactos econômicos adicionais na cidade. Os gastos dos residentes em São Paulo com o GPBFl são considerados simples substituição de impactos, uma vez que está sendo admitindo que tais gastos estariam ocorrendo naquela oportunidade em alguma outra atividade na cidade, anulando assim aquele primeiro efeito.

A avaliação dos impactos dos efeitos dos gastos diretamente associados ao evento foi feita considerando duas etapas: a de implantação e a de realização. Os principais mecanismos de transmissão dos efeitos dos gastos no setor produtivo, de acordo com a estrutura do modelo utilizado, podem ser classificados em três grandes grupos, a saber:

- efeitos diretos

- efeitos indiretos

- efeitos induzidos

Os efeitos diretos, indiretos e induzidos de choques de demanda final referem-se ao processo de produção e consumo de bens e serviços diretamente associados às estruturas de despesas dos organizadores do evento (alimentação, montagem de arquibancada, segurança, produção de ingressos etc.), da PMSP (arquibancada, obras de adequação do autódromo etc.), do pessoal envolvido no evento da Fórmula 1 e dos espectadores não-residentes na capital (hospedagem, alimentação, transporte etc.). 
Dentro do processo produtivo, a produçāo desses bens e serviços consome insumos intermediários (compras de outros bens e serviços) e remunera os fatores de produçāo. Assim, os gastos relacionados diretamente à produçāo de tais bens e serviços desencadeiam uma série de efeitos multiplicadores, com impactos diferenciados entre setores e regiōes (cidade, Estado de São Paulo e outros Estados). O resultado final dependerá da estrutura de produçāo das várias regiões, da distribuiçāo espacial dos gastos, do efeito-renda relacionado à remuneraçāo dos fatores de produçāo e ao padrāo de consumo das famílias, e finalmente da interdependência produtiva e espacial da economia brasileira, enfatizando-se a inserção de Sāo Paulo em um sistema inter-regional integrado.

Assim sendo, os diferentes impactos diretos, depois de identificados, alimentaram um modelo interestadual de insumo-produto (Estado de São Paulo versus restante do Brasil), integrado a um modelo regional de insumo-produto para a cidade de São Paulo. A integração do modelo municipal ao modelo interestadual fez-se necessária para a obtençāo de resultados espacialmente desagregados (desagregaçāo top-down). Assim, foi possível gerar resultados nāo apenas para a capital, mas também para o Estado de Sāo Paulo e outros Estados brasileiros.

\section{Fonte de dados e tratamento das informações}

Tendo como referência o Grande Prêmio Brasil de Fórmula 1, realizado no dia 6 de abril de 2003, foram levantados, analisados e compatibilizados dados de diversas fontes, cujas mais importantes passa-se agora a descrever.

No que se refere aos gastos da PMSP com a preparaçāo e adequaçāo do autódromo de Interlagos para o GPBFl de 2003, trabalhou-se com os dados fornecidos pela Secretaria Municipal de Esportes - SEME, que constam da Tabela 1. Foram necessários dois tipos de ajustes nesses dados. O primeiro refere-se à reclassificaçāo daqueles gastos da PMSP em termos dos bens e serviços produzidos pelos 42 setores de atividades, considerados nos modelos de insumo-produto utilizados na presente análise. $\mathrm{O}$ segundo tipo de ajuste refere-se à necessidade de eliminar todos os impostos indiretos que incidem sobre os valores daqueles gastos, a fim de avaliá-los a preços na esfera do produtor, ou seja, em termos do que se chama, em análises de insumo-produto, de preço básico.

Os resultados dessa compatibilização dos dados às exigências da metodologia utilizada sāo apresentados mais adiante, com os gastos dos demais parceiros do mesmo evento.
Tabela 1 Despesas da PMSP Com o Grande Prêmio Brasil de Fórmula 1 (por tipo)

(em R\$ de 2003)

\begin{tabular}{lr}
\hline \multicolumn{1}{c}{ Itens de despesas } & \multicolumn{1}{c}{ Valor } \\
\hline Arquibancadas & $9.247 .172,45$ \\
Telemetria & $1.038 .646,00$ \\
Suporte técnico & $3.491 .403,20$ \\
Aluguel de equipamentos de grande porte & $637.900,00$ \\
Limpeza & $716.800,00$ \\
Segurança & $704.000,00$ \\
Reforma e adequação do autódromo & $705.512,91$ \\
Reforma e readequação da pista do autódromo & $5.162 .019,79$ \\
Serviços técnico de sinalização & $172.082,94$ \\
Serviços técnico profissionais - EmuRB & $154.483,27$ \\
Adequação da área técnica - obra e serviços de complementação & $2.752 .439,60$ \\
\hline Total & $24.782 .460,16$ \\
\hline
\end{tabular}

Fonte: SEME-PMSP.

O segundo conjunto utilizado de dados de gastos com o GPBF 1 de 2003 foi o relativo às despesas de organizaçāo e realizaçāo desse evento, incorridas pela empresa organizadora (INTERPRO). As cifras consideradas na análise são as que constam da Tabela 2. Também no caso desses dados foi necessário proceder aos dois tipos de ajustes feitos no já mencionado caso dos gastos da PMSP, ou seja, reclassificaçāo dos itens de gastos em termos dos 42 setores de atividade e a sua revalorizaçāo a preços básicos. Os resultados desses ajustes também sāo apresentados mais adiante.

No caso dos dados dos gastos incorridos pelos indivíduos que pertencem aos grupos de participantes - pessoal da Fórmula 1 (pilotos, demais integrantes das equipes, autoridades e técnicos da FIA, jornalistas e convidados internacionais) e espectadores nāo-residentes na capital -, que compareceram ao autódromo de Interlagos para assistir ao GPBF1, a alternativa que se ofereceu foi a de sua estimaçāo. Para isso foram utilizadas as fontes de dados e os procedimentos que se passa a descrever de forma sucinta.

Os números dos diferentes tipos de participantes foram fornecidos pelos organizadores do evento, que estimou as seguintes cifras:

- Pessoal da Fórmula $1 \rightarrow 2.020$

- Equipes da F1 $\rightarrow 600$

- Fornecedores de componentes dos carros da F1 $\rightarrow 400$ 
- Autoridades, técnicos e convidados da FIA e da FOM $\rightarrow 500$

- Jornalistas internacionais $\rightarrow 520$

- Total do público assistente (pagantes e convidados) $\rightarrow 60.000$

Tabela 2 Despesas dos organizadores do Grande Prêmio Brasil de Fórmula 1 (por tipo)

(em $R \$$ de 2003)

\begin{tabular}{|c|c|c|c|}
\hline Itens de despesas & Produtos & Serviços & Total \\
\hline Alimentação & $1.448 .408,55$ & $308.347,12$ & $1.756 .755,67$ \\
\hline Assessoria de imprensa & & $99.088,00$ & $99.088,00$ \\
\hline Assessoria legal & & $60.541,00$ & $60.541,00$ \\
\hline Associaçōes/Confederaçōes/Federaçōes esportivas & & $652.538,86$ & $652.538,86$ \\
\hline Cenografia & $98.033,00$ & $312.600,35$ & $410.633,35$ \\
\hline Comunicação/Anatel & & $59.924,70$ & $59.924,70$ \\
\hline Engenharia & & $822.297,24$ & $822.297,24$ \\
\hline Impostos Pis/Cofins & & $2.040 .567,27$ & $2.040 .567,27$ \\
\hline Impressos/Cartazes/Gráfica & $576.363,46$ & & $576.363,46$ \\
\hline Locação de móveis & & $334.964,56$ & $334.964,56$ \\
\hline Logística interna & & $156.939,30$ & $156.939,30$ \\
\hline Montagem de arquibancadas & & $1.089 .629,00$ & $1.089 .629,00$ \\
\hline Montagens de estandes & & $394.961,57$ & $394.961,57$ \\
\hline Órgão esportivo/Direção de prova & & $1.077 .826,68$ & $1.077 .826,68$ \\
\hline Segurança & & $1.509 .496,21$ & $1.509 .496,21$ \\
\hline Seguros & & $828.627,68$ & $828.627,68$ \\
\hline Serviços diversos & & $78.183,87$ & $78.183,87$ \\
\hline Taxas da Polícia Militar & & $97.642,02$ & $97.642,02$ \\
\hline Taxas diretas PMSP & & $166.050,71$ & $166.050,71$ \\
\hline Transporte/Logística/Equipamentos & & $799.605,39$ & $799.605,39$ \\
\hline Uniformes & $77.071,99$ & & $77.071,99$ \\
\hline Venda de ingressos & & $638.440,45$ & $638.440,45$ \\
\hline Total & $2.199 .877,00$ & $11.528 .271,98$ & $13.728 .148,98$ \\
\hline
\end{tabular}

Fonte: INTERPRO.

Considerando, como já mencionado, que o público assistente relevante para a presente análise é aquele não-residente no município de São Paulo, utilizam-se dados da pesquisa feita em 2003 pela empresa Anhembi Turismo e Eventos da cidade de São Paulo, que se baseou em uma amostra de 500 pessoas que foram ao autódromo de Interlagos para assistir ao GPBFl. Com base nos resultados dessa pesquisa quanto ao quesito "origem do espectador", estimou-se a seguinte distribuição do público assistente, conforme dados na Tabela 3.
Tabela 3 Distribuição do público assistente segundo a sua origem

\begin{tabular}{lcc}
\hline Local de residência & № pessoas $^{\circ}$ & $\%$ \\
\hline Residente na cidade de São Paulo & 23.226 & $38,7 \%$ \\
Não-residente na cidade de São Paulo & 36.774 & $61,3 \%$ \\
Grande São Paulo & 3.024 & $5,0 \%$ \\
Estado de São Paulo & 5.806 & $9,7 \%$ \\
Outros Estados & 20.202 & $33,7 \%$ \\
Outros países & 7.742 & $12,9 \%$ \\
\hline
\end{tabular}

Fonte: Anhembi Turismo e Eventos, para as porcentagens.

No que se refere às estimativas dos padrões médios dos gastos diários e de números de pernoites na cidade de São Paulo de cada um desses vários subgrupos de participantes do GPBF1, utilizou-se as seguintes fontes de informações:

- informações sobre o perfil de gastos com hospedagem e número de pernoites do pessoal da Fórmula 1, fornecidas pelo Hotel Transamérica (local oficial de hospedagem dos principais desses participantes);

- pesquisa da embratur sobre os gastos dos turistas estrangeiros no país, utilizada para estimar o padrão médio diário dos demais gastos do pessoal da Fórmula 1, e também o padrão médio diário de todos os tipos de gastos do público espectador estrangeiro;

- a já mencionada pesquisa da Anhembi Turismo e Eventos, que estimou a distribuição dos espectadores do GPBF1 de 2003 segundo classes de valores da despesa diária total e classes de números de pernoites desses espectadores;

- pesquisa sobre o mercado do turismo doméstico no Brasil, realizada em 2003 pela FIPE para a EMBRATUR, que possibilitou estimar, para cada subgrupo de origem dos espectadores brasileiros não-locais, o padrão médio diário de todos os tipos de gastos.

Com essas informações básicas, foi então possível gerar vetores de demanda associados a todos os tipos de gastos realizados pelos participantes não-residentes na cidade de São Paulo, por conta do GPBFl. Esses participantes foram divididos nas seguintes cinco categorias: 
- pessoal da Fórmula 1;

- público da região metropolitana de São Paulo, exceto capital;

- público das demais cidades do Estado de São Paulo;

- público de outros Estados;

- público estrangeiro.

Para ter-se uma idéia da magnitude e da composição dos gastos estimados para essas várias categorias de participantes do GPBFl, apresenta-se a seguir, na Tabela 4, os valores do gasto total médio diário, bem como o número médio de pernoites e do gasto total obtido para cada um desses grupos.

Tabela 4 Magnitude e estrutura dos gastos do total de participantes do GPBF 1 em 2003

(em $R \$$ de 2003)

\begin{tabular}{lccrr}
\hline & $\begin{array}{c}\text { Gasto total } \\
\text { diário médio }\end{array}$ & $\begin{array}{c}\text { N }^{\underline{0}} \text { de } \\
\text { diárias }\end{array}$ & $\begin{array}{c}\text { № de } \\
\text { pessoas }\end{array}$ & $\begin{array}{r}\text { Gasto total } \\
\text { da categoria }\end{array}$ \\
\hline Pessoal da Fórmula 1 & 638,32 & 5 & 2.020 & $6.447 .000,81$ \\
Público da RMSP, exceto capital & 67,62 & 1 & 3.024 & $204.500,59$ \\
$\begin{array}{l}\text { Público do Estado de São Paulo, } \\
\quad 133,43\end{array}$ & 2 & 5.806 & $1.549 .466,77$ \\
$\quad$ exceto RMSP & & & & \\
Público de outros estados & 287,07 & 3 & 20.202 & $17.398 .110,57$ \\
Público de outros países & 420,00 & 5 & 7.742 & $16.258 .064,52$ \\
\hline
\end{tabular}

Adicionalmente, apresenta-se na Tabela 5, a seguir, a distribuição do total dos gastos de todas as cinco categorias de participantes, em termos dos bens e serviços produzidos pelos 42 setores de atividades considerados na análise. Nessa mesma tabela, também aparece a já anteriormente mencionada distribuição dos gastos da PMSP e dos organizadores do evento, em termos dos mesmos 42 setores de atividade.

A partir desses vetores de demandas, ou "choques" iniciais, dos gastos de cada uma das partes envolvidas na preparação e realização do GPBF 1, foram estabelecidas as simulaçōes dos impactos totais desses gastos, resultante da cadeia de inter-relaçōes setoriais e regionais da estrutura produtiva requerida para produzir aquelas demandas de bens e serviços. Para tanto, utilizou-se dos dois já mencionados modelos de insumo-produto, sendo o primeiro de âmbito nacional, regionalizado para duas grandes regiōes (estado de São Paulo e restante do país), e o segundo de natureza regional para o município de São Paulo.

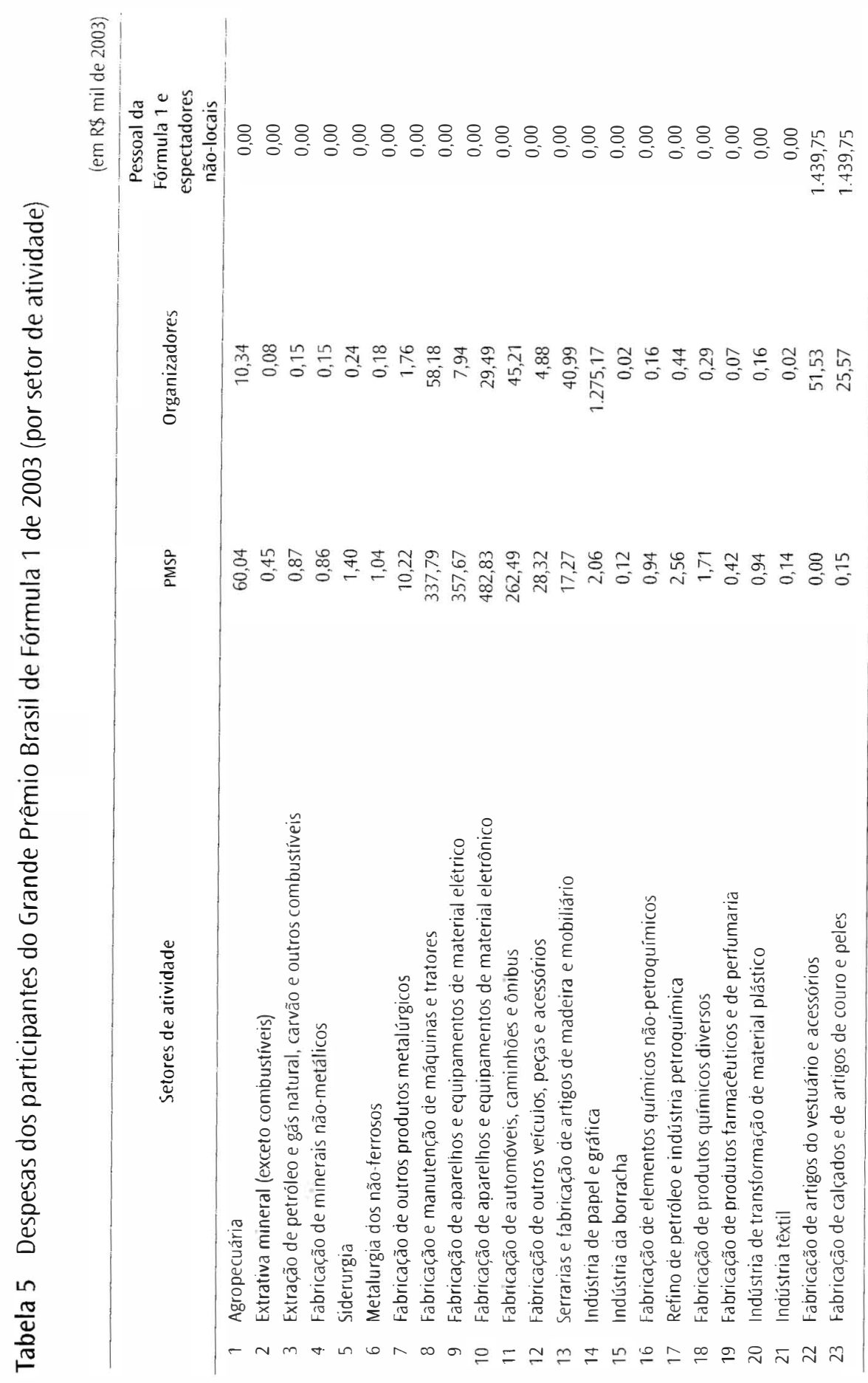




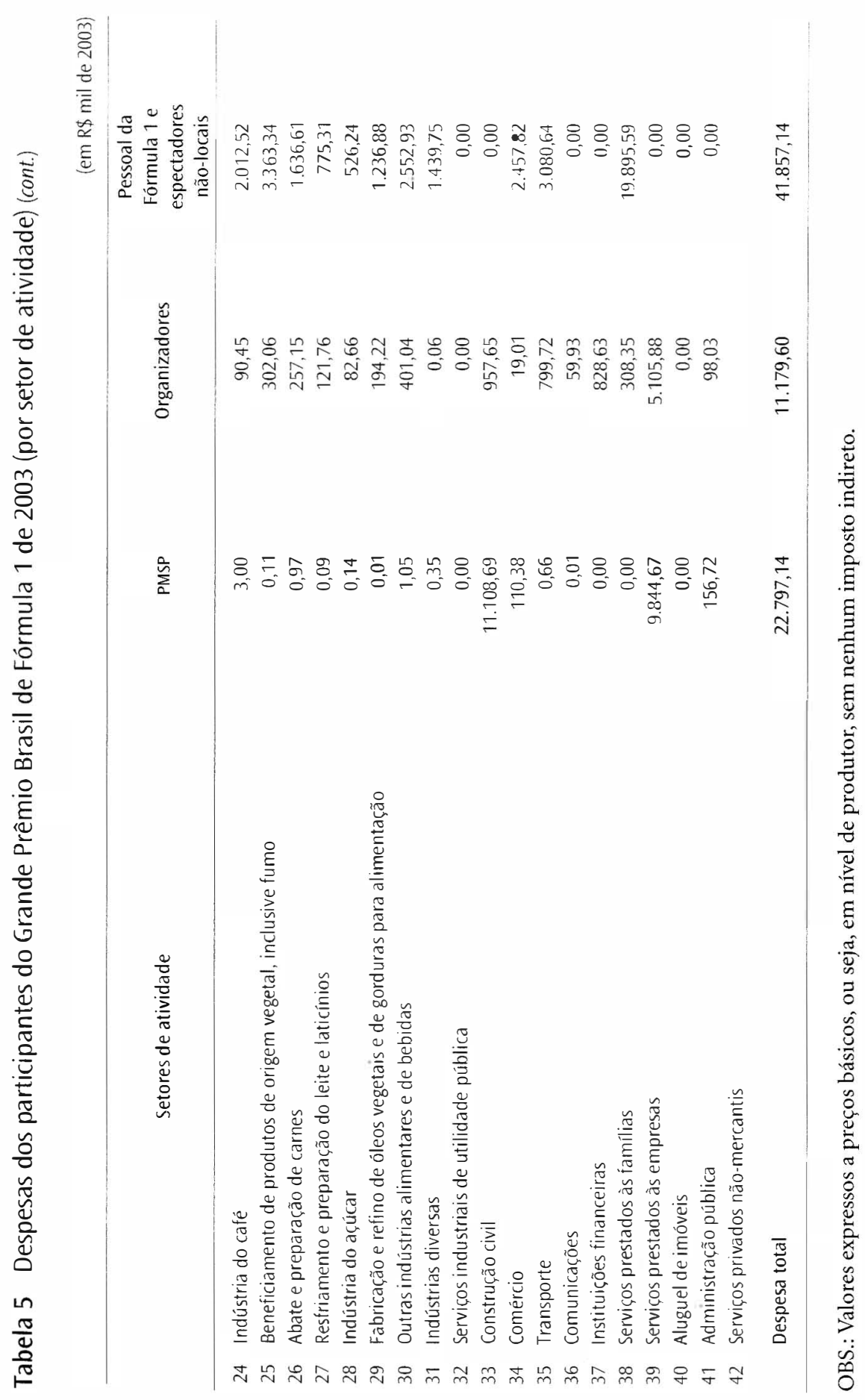

\section{Resultados}

Os principais resultados obtidos na análise dos impactos econômicos do GPBF1 de 2003 estão sintetizados nas Tabelas 6, 7 e 8. Nestas tabelas aparecem, respectivamente, os resultados relativos aos impactos sobre produção, valor adicionado (ou renda) e emprego, impactos esses mensurados segundo sua área geográfica de incidência, a saber: município de São Paulo; demais regiões do Estado de São Paulo e outros Estados do país.

Considerando que todos os impactos são decorrentes da despesa total de $\mathrm{R} \$$ 80,368 milhões estimada para o evento analisado-total esse composto por $\mathrm{R} \$ 24,782$ milhões gastos pela PMSP, $\mathrm{R} \$ 13,728$ milhões gastos pelos organizadores e $\mathrm{R} \$ 41,857$ milhões incorridos por todos os participantes e espectadores -, cabe destacar um primeiro resultado muito importante: a despeito do fato de a PMSP ser responsável por cerca de apenas um terço dos recursos injetados na economia da cidade de São Paulo por conta do evento, pode-se considerar que os outros dois terços representam um efeito de gastos induzido pelo investimento da PMSP, uma vez que, pelo menos nesta cidade, o GPBF1 dificilmente seria realizado sem esse apoio.

Assim, pode-se considerar que, do ponto de vista da sua capacidade de gerar impactos econômicos, certamente o investimento da PMSP no evento possui um dos maiores coeficientes de alavancagem de recursos: para cada $R \$ 1,00$ de recurso investido no evento, a PMSP consegue induzir que $R \$ 3,20$ sejam injetados na economia da cidade. E como se verá a seguir, é esse fator o responsável pelos substantivos impactos econômicos dessa política da PMSP.

Antes de analisar especificamente os resultados dos impactos econômicos de aumentos de produção, de renda e de emprego, é pertinente destacar que as três tabelas que contêm esses resultados foram estruturadas da mesma forma. Em primeiro lugar, aparece, para cada coluna de participante responsável pelo gasto ou efeito inicial, o efeito total (de produção, renda ou emprego) induzido pelo mesmo gasto. Esse efeito total é, por seu turno, desagregado pela região geográfica de incidência.

Em seguida aparecem, também por tipo de participante e de região geográfica de incidência, o chamado efeito líquido total, que corresponde à diferença entre o efeito total e o efeito inicial, ou mais propriamente, o efeito indireto implicado pelo choque inicial do gasto.

Por último, ao final das tabelas, são apresentados indicadores sintéticos das simulações. As definições dos indicadores tradicionais são apresentadas a seguir:

- Multiplicador de produçāo: valor total da produção em todos os setores da economia, necessário para satisfazer uma unidade monetária adicional de gastos típicos de um determinado grupo (organizadores, PMSP, equipes etc.); 
- Multiplicador de emprego tipo I: empregos criados na economia como um todo para cada emprego criado diretamente pelas despesas de um determinado grupo;

- Multiplicador de valor adicionado tipo I: total do valor adicionado criado na economia como um todo para cada unidade monetária de valor criada diretamente pelas despesas típicas de um determinado grupo.

Além das versões tradicionais desses indicadores, foram calculados multiplicadores específicos para as despesas da PMSP, em que se considera a relação entre o efeito total sobre produção, renda ou emprego e o respectivo efeito inicial da parcela das despesas que cabe à PMSP. Trata-se do indicador que permite levar em conta o já mencionado poder de alavancagem de recursos dos gastos da PMSP. Indicadores análogos também foram definidos para mensurar a relação entre os específicos efeitos totais sobre o município de São Paulo e as despesas da prefeitura.

Finalmente, e apenas na Tabela 8, apresenta-se o indicador custo de "criação" de um emprego, associado a cada uma das categorias de participante que realizam os gastos.

Isto posto, pode-se destacar inicialmente na Tabela $7^{4}$, que o montante de $R \$ 80,368$ milhões de despesas associadas ao GPBFl e injetados na economia da cidade de São Paulo consegue gerar, direta e indiretamente, um aumento de renda de $R \$ 62,617$ milhões no país como um todo, sendo que cerca de $75 \%$ desse aumento ocorre na própria cidade de São Paulo, $8 \%$ no restante do Estado de São Paulo e $17 \%$ nos demais Estados.

Em relação a esses resultados vale a pena chamar a atenção para dois aspectos. O primeiro diz respeito ao fato de a cidade de São Paulo conseguir "capturar" ou internalizar cerca de 3/4 do impacto total. Como se verá, isso decorre não só da natureza altamente diversificada da estrutura produtiva desta cidade - que, portanto, consegue suprir grande parte dos bens e serviços demandados pelos participantes do evento -, mas também do fato de uma parcela substancial dessas demandas ser dirigida aos setores da construção civil e de serviços, como alojamento, alimentação, serviços empresariais diversos, lazer etc., que são produzidos na mesma região em que são consumidos.

O segundo aspecto diz respeito ao fato de que, embora o choque inicial dos gastos totais do GPBFl resulte num poder multiplicador de aumento de renda total

4. Embora os primeiros resultados apresentados refiram-se aos impactos sobre o valor da produçāo na economia, julgou-se pertinente comentar os resultados mais interessantes e que se referem aos impactos sobre o valor adicionado (renda) e o emprego da māo-de-obra. na economia (multiplicador de 0,78 ) comparável à de muitos outros projetos e políticas que a PMSP poderia implementar ${ }^{5}$ - caso se considere que os $R \$ 62,617$ milhões de aumento de renda no país são, em última instância, conseqüência dos R \$ 24,782 milhões de gastos da PMSP -, pode-se considerar que existirão muitos poucos projetos ou programas da PMSP que possam apresentar um poder de multiplicação de renda comparável ao da participação desta no Gip̉sF 1 (multiplicador de renda de 2,5). Mesmo que a avaliação fique restrita apenas ao aumento de renda na jurisdição da PMSP, constata-se que os $R \$ 24,782$ milhões de gastos da PMSP com o (jPBFl de 2003 conseguiu gerar $R \$ 47,156$ milhões de aumento de renda na cidade de São Paulo (ou seja, com um alto multiplicador de renda parcial de 1,9).

No que diz respeito ao poder de geração de empregos, constata-se na Tabela 8 que o GPBFl de 2003 foi responsável pela "criação" de 14.071 empregos no país, sendo que $68 \%$ destes na cidade de São Paulo, 7\% nas demais regiões do Estado de São Paulo e 25\% nos outros Estados. Em relação a esses resultados, é necessário chamar a atenção para o conceito de emprego utilizado, que se refere a "equivalente homem-ano" (EHA), ou seja, o conteúdo de trabalhadores-ano necessário para satisfazer a demanda adicional na economia gerada pelo evento. Sendo assim, dadas as características do mercado de trabalho, os valores apresentados para impacto sobre emprego em termos de EHA não significam que aquele total de 14.071 novos empregos foi necessariamente criado.

Finalmente, ainda em relação à geração de empregos, vale a pena destacar que o custo médio total de "criação" de um emprego associado ao GPBFl de 2003 é relativamente baixo e equivale ao desembolso de $\mathrm{R} \$ 5.711,58$. Caso se considere apenas os gastos da PMSP, esse custo é ainda mais baixo, atingindo $\mathrm{R} \$ 1.761,24$ para empregos gerados em qualquer região do país, e $\mathrm{R} \$ 2.599,87$ para os empregos gerados na capital.

Esses resultados indicam que o alto poder gerador de empregos do GPBFl 1 pode ser também explicado pelas características dos setores de atividades, que são mais fortemente influenciados pelos gastos associados a esse evento.

Isso pode ser constatado nas Tabelas 9 e 10, nas quais se apresentam os resultados dos impactos na renda e no emprego, classificados por setor de atividade e por região de incidência.

5. Esse tipo de multiplicador sempre apresenta valor menor que um, dado que parte do valor do choque inicial corresponde a impostos indiretos embutidos nos preços de mercado e que, portanto, nāo tem poder de geraçāo de renda nos setores produtivos da economia, e outra parcela se transforma em vazamentos de renda do país pela utilizaçāo de insumos importados para produzir os bens demandados. 

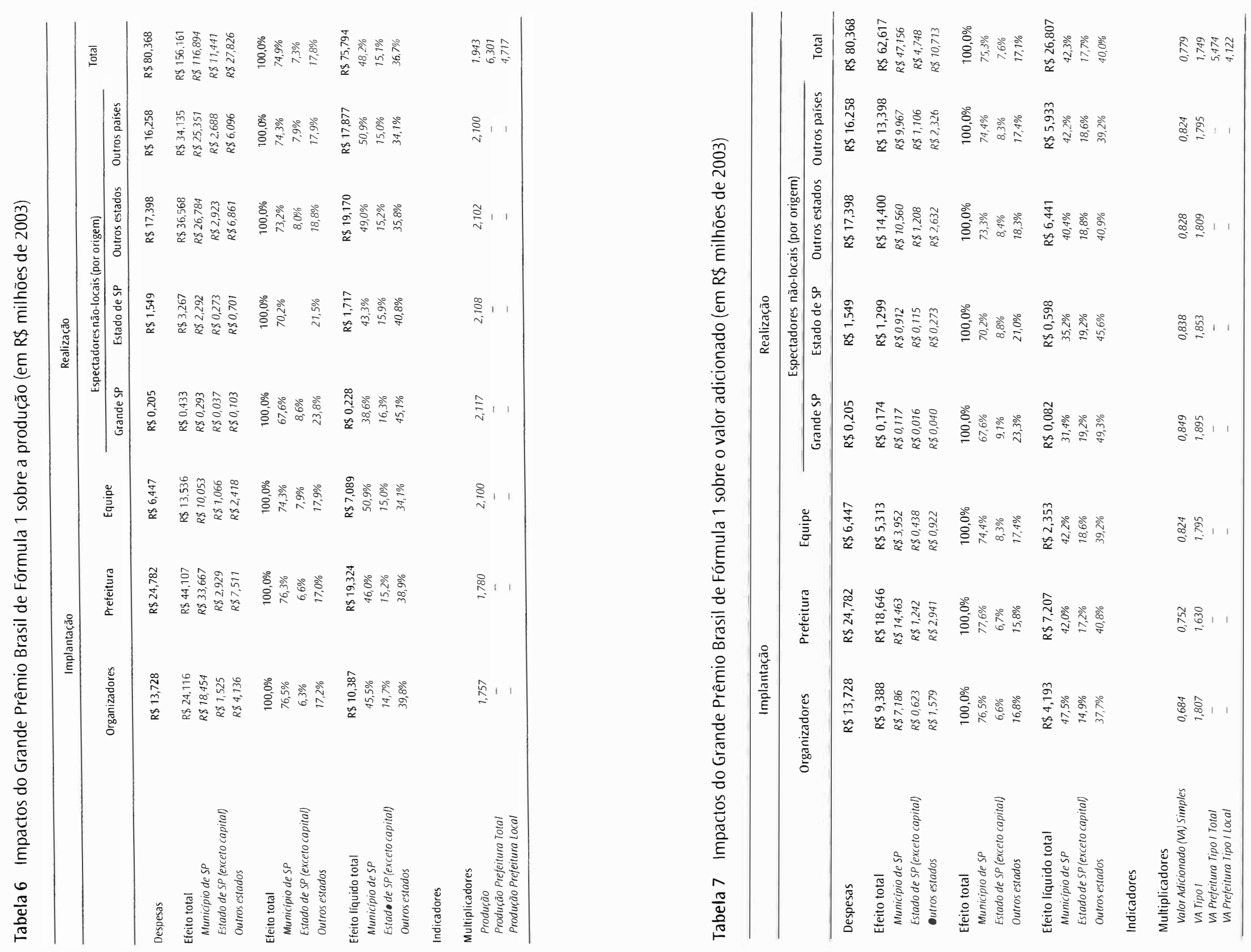

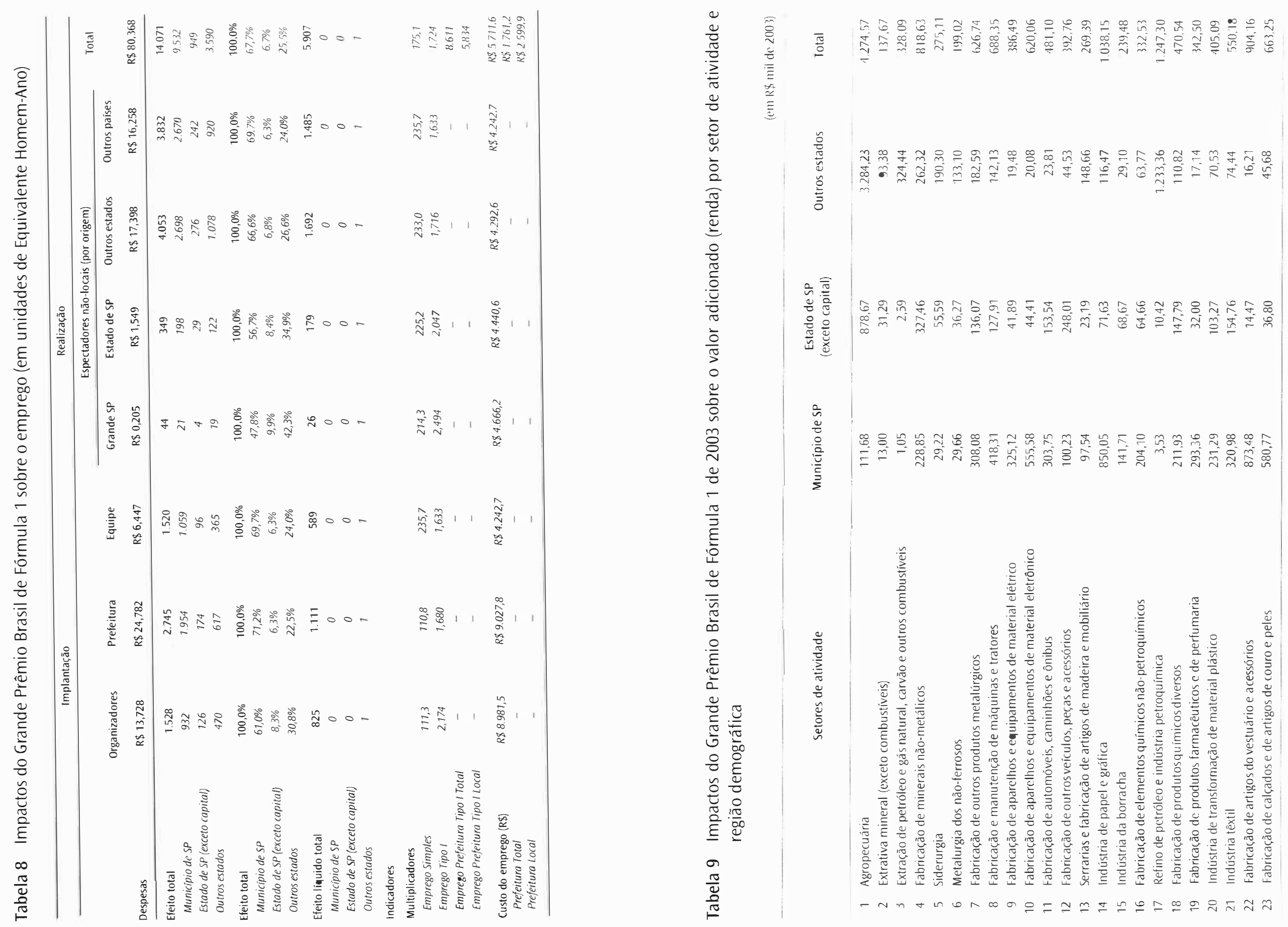

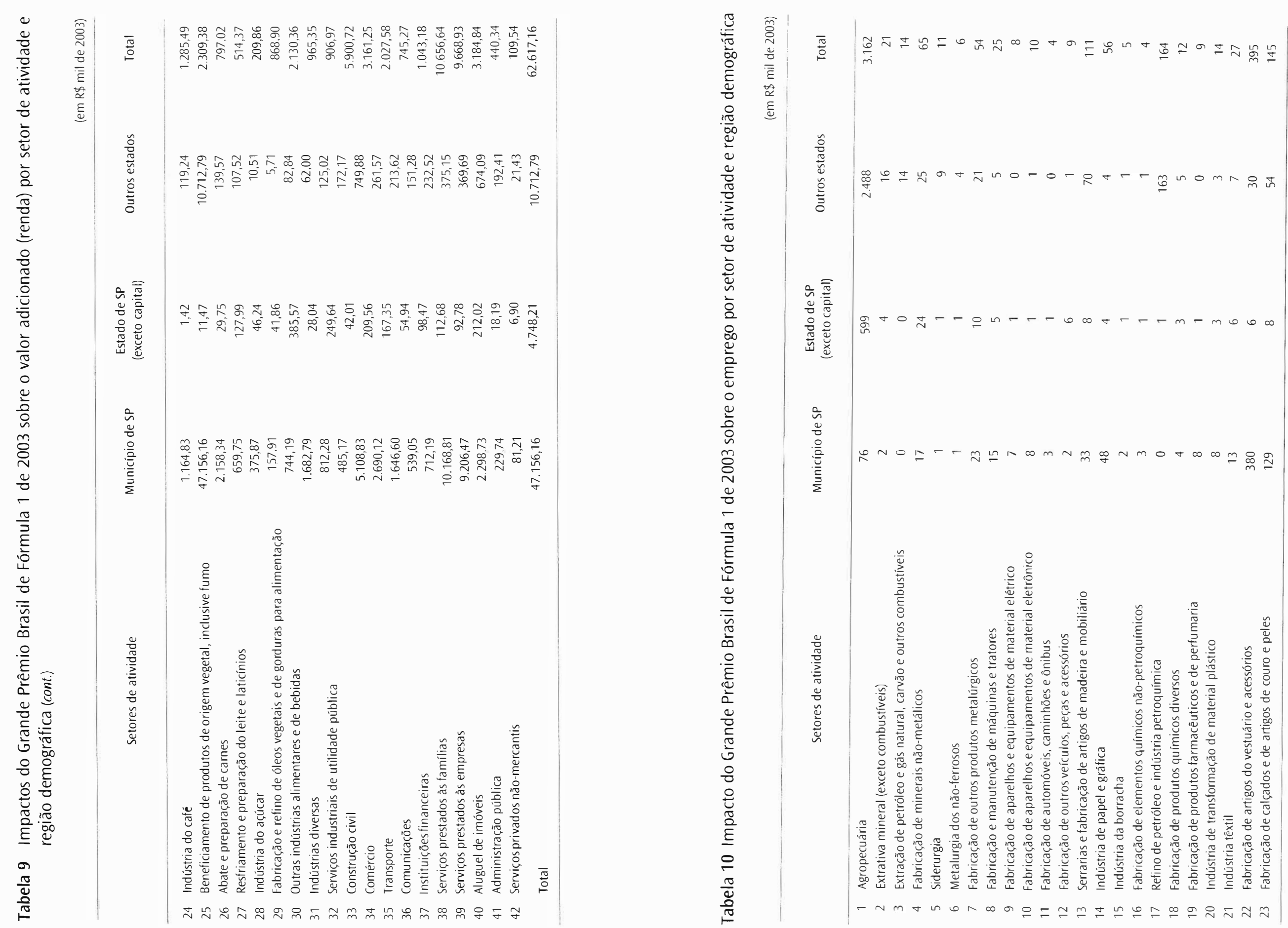


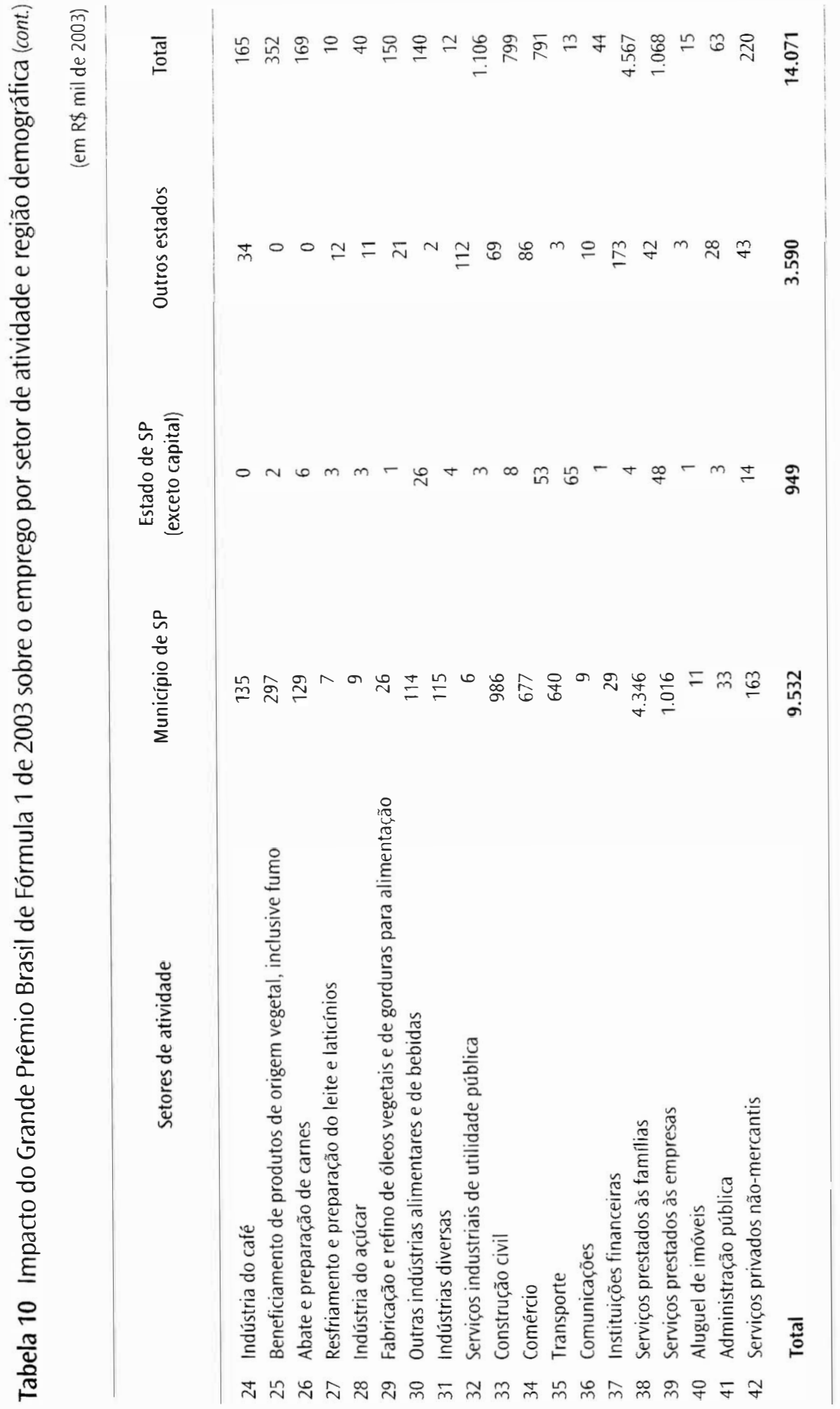

Como já mencionado anteriormente, o setor que recebe os maiores benefícios do aumento de demanda associado ao GPBF 1 é o de serviços prestados às empresas, às famílias e à construção civil, que estão entre os setores para os quais a cidade de São Paulo consegue suprir a demanda sem a necessidade de importaçōes de outras regiōes do país e que apresentam os maiores coeficientes de absorção de mão-de-obra.

\section{Referências bibliográficas}

ALLARDICE, D. \& HEWINGS, G. J. D. 2003. Analysis of the potential impacts of the 2006 Super Bowl on the Detroit Metropolitan economy. Lawrence Technological University and Regional Economics Applications Laboratory, University of Illinois, Urbana-Champaign, report. ARTHUR Andersen \& Center for Regional Economic Analysis. 1999. Economic impact study of the Sydney 2000 Olympic Games, full report.

HEWINGS, G. J. D. 2004. Economic impact of the LaSalle Banks Chicago Marathon, 2003. Regional Economics Applications Laboratory, University of Illinois, Urbana-Champaign, report. MILLER, R. E. \& BLAIR, P. 1985. Input-outputanalysis: foundations and extensions. Englewood Cliffs, NJ: Prentice-Hall.

MOTORSPORT Industry Association. 2003. The economic impact of the 2002 FIA Foster's British Grand Prix, final report

Recebido em 08/08/2004.

Aprovado em 06/09/2004 